\title{
Rating System in Training Specialists for Coal Mining Region Enterprises
}

\author{
Roman Islamov ${ }^{1}$, and Tatyana Sergeychick ${ }^{1, *}$ \\ ${ }^{1}$ Kemerovo State University, Institute of Philology, Foreign Languages and Mediacommunications, \\ Department of Foreign Languages, 650000, 6 Krasnaya st., Kemerovo, Russia
}

\begin{abstract}
This paper is devoted to the experience of implementing the Rating System for Students' Performance Assessment at the institution of higher education (Kemerovo State University) in coal-mining region. The focus is on the description of the Rating System and review of its key objectives in the process of training specialists for mining enterprises of Kuzbass. The assessment of students' progress consists of grades for different activities such as studies, research, participation in sports competitions as well as social and cultural events. The purpose of paper is to evaluate the experience of implementing the Students' Rating System at Kemerovo State University from the point of view of students as standard users. The paper highlights the results of the survey held among the students of the University on using the Rating System. The survey discovers its advantages such as motivating power, the ability to promote students' academic activity, unbiased evaluation, convenience, etc. The Rating System is used as an important assessment tool in training future engineers, economists, exploration geologists, environmental managers etc. for coal-mining enterprises in Kuzbass region.
\end{abstract}

\section{Introduction}

Since 2002 according to the Order of the Ministry of Education and Science of the Russian Federation "On Carrying Out an Experiment on the Implementing a Students' Academic Performance Rating System at Institutions of Higher Education" Russian universities have started the development of the database (storage) engine to collect and process the student progress data. Several leading universities of the Russian Federation were pioneers in this experiment.

The complex quality assessment of student progress in studies for the basic programs of higher education is regarded as a central objective of the rating system. The main purposes for implementing the rating system assigned by the Ministry Order are (i) to increase the students' motivation for mastering educational programs by means of highly differentiated assessment of their progress, and (ii) to increase the level of organizing the educational process at institutions of higher education.

\footnotetext{
${ }^{*}$ Corresponding author: 1alli8@mail.ru
} 
Later, as part of the reform, the new federal state education standards (in the format called "third generation") included the requirement for developing the objective assessment methods for students' knowledge and skills, as well as graduates' competences.

Since 2010 the development of Learning management system has begun at Kemerovo State University. The professional training of specialists for the coal-mining industry in Kuzbass began at this institution of higher education in 1950s

The Instruction on the Rating System for Students' Performance Assessment at Kemerovo State University has been changed four times according to normative documents, but all these editions kept the essence of the main goal and key principles of academic grading. The system is aimed to assess all types of student's activities with the use of rating component. The system has been also technically improved with regard to the experience of its use.

The last edition of this Instruction issued in 2016 (accepted at the end of 2015), defines the Rating System for Students' Performance Assessment (Students' Rating System) as a complex of operations providing quality assessment of students' academic activities and scientific research carried out in terms of the basic programs of higher education, along with the balanced development of creativity and sports skills.

The assessment of student progress consists of several numeric grades for different activities of a student such as studies, research, participation in sports competitions as well as social and cultural events. It includes calculation of the student's current end-of-term rating and overall progress rating for the period of training.

The proper assessment of students' progress is vital in preparing future specialists for coal-mining region. The purpose of this article is to evaluate the experience of implementing the Students' Rating System at Kemerovo State University from the point of view of students as standard users. We also aim to draw the attention of the university teachers to some aspects of organizing the process of Assessment for the Students' Rating System.

\section{Materials and Methods}

The research presents the experience of implementing the Rating System for Students' Performance Assessment (Students' Rating System) at Kemerovo State University (Kemerovo), the leading institution of higher education in training specialists for mining industry in Kuzbass. The qualitative study began in 2015 and stopped in 2019.

In preparing the article the following methods and materials were used: reviews of the regulatory documents on the Implementing the Students' Academic Performance Rating System at institutions of higher education, reviews of publications concerned with the problem of rating assessment of students' progress at institutions of higher education; a survey to investigate the opinions of students and teachers about the Rating System, qualitative structured interviews with teachers (129 interviewees) and students (314 interviewees) of Kemerovo State University to examine attitudes toward the Students' Rating System; observation, analyzing our own experience of using the Rating System for Students' Performance Assessment (Students' Rating System) at the university.

\section{Results and Discussion}

One component of the Learning management systems at Kemerovo State University is the Students' Rating System for studies, students' research activities, sports achievements and creative works. The Students' Rating System is used as a tool to evaluate the activities in the fields of science, education and training at the university. 
According to the Instruction on the Rating System for Students' Performance Assessment at Kemerovo State University, the general mission of the Rating System consists in the objective and reliable assignment of academic grades for the students. The key purposes for the use of Students' Rating System include implementing the personcentered approach to teaching, encouraging systematic student engagement and motivation, supporting their creative abilities, providing differentiated assessment for students' achievements in course of transition to a new education model.

The Rating System gives a student the opportunity to monitor their performance in academic disciplines on a regular basis, to evaluate one's scientific potential as well as to arrange their time for the required current independent activity. The declaration of the current rating assessment for each academic discipline and its change is aimed to provide students with the understanding of necessity for systematic work toward a degree.

Thus, the Instruction on Students' Academic Performance Rating System assigns the following key objectives for the rating system at Kemerovo State University:

- to support the motivation of students for steady intensive work either during a semester or academic year, or the entire period of training;

- to promote the efficiency of compulsory independent activities of students;

- to improve managing students' regular work in course of mastering educational programs by means of highly differentiated assessment of their progress in studies;

- to encourage self-discipline and responsibility of students for their progress;

- to obtain the objective assessment of competences development in graduates.

In this study, we intend to find out how students of the university evaluate the functioning of the rating system at Kemerovo State University. Certainly, experts in the field of information and communication technologies and programming are capable to estimate the technical characteristics of the system. Also, the students mastering the programs for computer sciences degree are able to make up a professional opinion on technical aspects of the Students' Rating System.

However, the applied aspect in the use of the rating system can be estimated quite clearly by non-specialists. Using the Students' Rating System every day, we wanted to estimate its functional features such as convenience, availability, capacity to accomplish the goals set for the system, etc.

Obviously, a solution to the problem of managing students' regular work in course of mastering educational programs by means of highly differentiated assessment of their progress in studies is involved to a certain extent in the technical design of the Students' Rating System. The system allows to organize technical collection and record of student grades in academic rating as well as one's achievements in extracurricular activities. It also gives the opportunity for the university administration to automate these processes in order to examine and manipulate the data.

To measure the efficiency of implementing the Students' Rating System we asked users among students to make a conclusion about its advantages. We are interested whether the general idea of the rating system is justified, whether its format and model are acceptable. It is important to estimate in general whether the system is necessary for them or not, as well as how reasonable its implementation is. Finally, it is crucial that its use corresponds with the framework of the Instruction on the Rating System for Students' Performance Assessment at Kemerovo State University. The surveys and interviews were held among students taking their courses for both Bachelor's and Master's Degree in Biology, Applied Mathematics, Pedagogical Education and others.

At the beginning of the study we decided to find out whether students use their account on the Rating System. Indeed, the Instruction on the Rating System for Students' Performance Assessment at Kemerovo State University prescribes the teachers to fill in the database with the students' grades in an orderly manner. As for students, however, there is 
no rule which would oblige them to monitor their rating. For students, keeping track of their progress is voluntary, so the first thing that is important for us is to understand the relevance of the Rating System facility. The survey revealed that $97 \%$ of the respondents use the Students' Rating System of Kemerovo State University: 5\% of them use it every day, $29 \%$ - do it on a quite regular basis, $43 \%$ - use it occasionally (from time to time), $20 \%$ - refer to it seldom. $3 \%$ of respondents answered that they never use the Students' Rating System facility.

During one-to-one and group interviews students of bachelor programs explain that at the beginning of their studies at university, it was extremely important for them to keep track of their progress. The Rating System for the first-year students reveals their level of knowledge in the new education institution, allows to bring some lucidity which is necessary in the difficult period of their adaptation.

Despite the survey proves high relevance of the Rating System facility for the vast majority of respondents, the students of master's degree programs, especially those who have completed their bachelor's course at Kemerovo State University, expressed strong indifference for it in the interviews. They are not in the habit of using the Rating System at all, as they are not used to it since there was not any at the time they took their bachelor's course.

Programmers at Kemerovo State University have designed quite a simple database system which provides substantial clarity in the assessment of students' progress. This is a percentage-based grading system (which corresponds with the traditional five-grade system), so each assignment is given a percentage score. The final grade of a student represents a stated proportion of different types of work such as report, project, testing, attendance, independent activity and others. This system aids to evaluate the students' learning of the material and the complex understanding of the course material. Besides, the system provides the opportunity to compare what students achieve in the same group, with the same teacher, at the same lessons and from homework during the same time period.

As long as one of the key purposes of the Rating System consists in obtaining the objective assessment to the development of students' competences, we included the question about the unbiased evaluation in the survey. Indeed, this is the crucial issue for students, because teachers award grades - both at school, and in the institution of higher education - with a different precision rate $[1,9]$. The assessment is often individualized, and sometimes, unfortunately, is biased, being in conflict with the accepted grading scale.

The survey among students on how the Rating system contributes to the objectivity of assessment has showed the following results: $27 \%$ of respondents agreed that the system promotes objectivity, $37 \%$ of students answered that it "sometimes" promotes objectivity, $22 \%$ expressed disagreement, $14 \%$ found it difficult to answer this question. Thus, it has been found that the Students' Rating System demonstrates the apprehensible success in solution to the problem of unbiased evaluation. More than a half of the respondents namely $64 \%$ of students - recognize to some extent the benefits of the system in obtaining the objective assessment.

Nevertheless, the doubt which is expressed in $22 \%$ negative opinions signifies the fact that many students do not believe in teachers' objectivity in evaluation of their knowledge. In addition, the fact that comparatively large amount of students still cannot understand clearly the reliability of assessment at the university is also disappointing.

This could be the result of one more pressing issue in the use of the Rating System which is concerned with filling, or to be exact - not filling it in by teachers. Despite the rapid increase in the number of multimedia laboratories at Kemerovo State University in recent years [6], not all teachers hold classes in the computerized rooms. Since a teacher has no access to a computer, there is no opportunity for timely filling in the grades into the system. Many students are aware of this problem and understand the difficulties, though in 
their questionnaires they express the strong need for timely informing students on their progress.

One of the main reasons of implementing the Rating System for Students' Performance Assessment at Kemerovo State University is to support the motivation of students for steady intensive work for the period of their training.

In attempt to determine the motivating potential score of the Rating System, we asked students a direct question of how it affects their progress. The positive correlation between the availability of the rating system in education institution and such difficult psychological phenomenon as motivation to learn, doesn't not seem certain to us at first sight, nevertheless, the survey has showed that $40 \%$ of students feel this correlation. It is remarkable that $28 \%$ of respondents consider the influence of the Rating System on their progress as positive, but $12 \%$ of students estimate it as negative. The number of students who stated that the Rating System does not affect their progress in any way (does not motivate) is $51 \%$, which was predictably high; $10 \%$ of respondents found it difficult to answer this question.

At the same time, some teachers using the Rating System consider that the idea of competitiveness makes the framework of the system itself. Therefore, considering that the phenomenon of motivation is connected with a number of factors which induce a person to work (that is motivate a student to study) [3,4], we decided to measure the motivating power of the Rating System indirectly - through the factors inspiring such motivation. Competitiveness in educational environment is traditionally considered as contributing to progress of students. In other words, creating a competitive environment for training by teacher provides the required motivation of students to study.

In the survey, students were asked a question whether Rating System made them compete with others in their group. It has been found that for nearly a half of respondents $49 \%$ of students - the Rating System makes them compete more or less. For $18 \%$ of students the Rating System becomes an incentive to a competition to be the best in their group, $24 \%$ of respondents "sometimes" join the process of competition. The desire to "seldom" take part in such competition is expressed by $7 \%$ of students; $5 \%$ of respondents found it difficult to answer the question. $44 \%$ of students answer that the Rating System does not make them compete with the fellow students.

In one-to-one interview, teachers agreed, taking into consideration their pedagogical experience, that the Rating System pushes some students to their best performance potential by appealing to their competitive instincts. The Rating System serves as a convincing tool for organizing and motivating students to work systematically.

In addition, our observation proves that the aspiration to be the best in their group is more obvious among the students of the first and second years of study for bachelor's degree. This is due to their ambitions to earn the reputation of a stellar student.

However, the motivating function of the Students' Rating System is understood in different ways by the teachers $[2,7,10]$. Of course, the grading system based on specific assessment scale is provided by the discipline program. But the Rating System for Students' Performance Assessment at Kemerovo State University presents a great deal of freedom for teachers in awarding grades for different types of students' work. So, several teachers award academic grades taking into account the terms of completing a task by a student. This issue includes ways for students to lose high grades despite having actual understanding of the course material. Such approach in assigning grades is reasonable enough, because it considers the ability of students to do the required work on time. Nevertheless, using academic grades to penalize for being behind a schedule discourages students from steady intensive work.

In practice the system of academic grading allowing to lose scores in rating leads to two opposing categories of students in one group - the top-performing students and poor- 
performing students. For the better adapted students this way of assigning grades becomes motivating. But those lacking time management skills suffer from the extreme despair, which results in academic failure, dissatisfaction with studies, frustration, and even dropping out of the university [8]. Thus, the teachers should search for the ways for socalled "productive" motivation when using the Students' Rating System [5].

At the final part of the survey we include a question about the importance to fill in the Students' Rating System by teachers in a timely and orderly manner: $90 \%$ of respondents answered in the affirmative, $2 \%$ of answers were in the negative, $8 \%$ of students expressed indifference ("no matter"). The answers give an opportunity to estimate the prospects for implementing and use of the system. Moreover, the high need in functioning of the Rating System expressed by students balances some unfavorable results of the survey described above.

Along with the multiple choice questions in the survey there were open ended questions concerning advantages and disadvantages of the Rating System for Students' Performance Assessment at Kemerovo State University. The students were able to respond in open text format to express their understanding as well as ideas, opinions etc. The answers were very different. "Convenience", "an opportunity to keep track of the progress" were prevailing among positive characteristics of the Students' Rating System. However, there were also several negative reviews, for example, about the design of the website for the Rating System - some considered it too simple. A number of students in the questionnaires criticized the website for technical failures - slow loading, problems with password reset, etc.

However, the majority of remarks are concerned with the use of the Students' Rating System by teachers. Many students ( $80 \%$ of respondents) expressed their regret at the improper filling in the database by the teachers. Some students wrote that they were not satisfied with lack of uniformity in academic grading on different subjects, as well as assessment was not always clear and accurate, complaining for no criteria in the Rating System itself along with no clear understanding how to earn credit for the desired examination grade. One student stated this problem as "a priority of grades over real student's progress". Thus, much criticism concerns not the Students' Rating System itself but the lack of feedback and teacher's unwillingness to inform students about the requirements for their good progress.

\section{Conclusion}

The general conclusion for the research is that the Rating System for Students' Performance Assessment at Kemerovo State University functions properly enough. Due to its advantages such as ease and convenience of use, motivating power, the ability to promote students' academic activity, unbiased evaluation, the Rating System is appropriate to modernize training future specialists for coal-mining enterprises in Kuzbass region.

The Rating System as an assessment tool provides students with a clear understanding how to earn credits for a desired grade. This definitely has a motivating effect for many students that drives them to be at their best performance due to competition.

Students' motivation for success in their professional studies is a positive factor for the future sustainable development of the mining region. The administration of the region demonstrates substantial interest in training highly qualified engineers, economists, exploration geologists, environmental managers, etc. So, the aim of Kemerovo State University is to exert best efforts in developing educational potential for the progress of the mining industry in Kuzbass. 


\section{References}

1. S. P. Buckelew, N. Byrd, C. W. Key, J. Thornton, M. M. Merwin, Teach. Psychol., 40:2, 134-138 (2013)

2. T. R. Guskey NASSP Bulletin, 95:2, 85-98 (2011)

3. G. R. Kiany, P. Shayestefar, Br. J. Educ. Psychol., 81:3, 491-508 (2011)

4. L. I. McCann, K. R. Immel, T. L. Kadah-Ammeter, S. J. Priniski, Teach. Psychol., 40:3, 228-232 (2013)

5. C. M. Peterson, T. O. Peterson, J. Manag. Educ., 40:4, 415-431 (2016)

6. M. Ryabova, T. Sergeychick, E3S Web Conf., 41, 04039 (2018)

7. T. L. Stephens, Encouraging Positive Student Engagement and Motivation: Tips for Teachers (Pearson, London, 2015)

8. W. Stroebe, Perspect., Psychol. Sci., 11:6, 800-816 (2016)

9. T. M. Tripp, L. Jiang, K. Olson, M. J. Graso, Mark. Educ., 5:3, 105 (2018)

10. N. Zepke, L. Leach, Active Learn. High. Educ., 11:3, 167-177 (2010) 